\title{
LAS CIUDADES ESCONDIDAS
}

EMILIANO RUIZ 


\section{EMILIANO RUIZ}

Arquitecto. Facultad de Arquitectura, Universidad oRT Uruguay. Actividad profesional independiente. Profesor asistente de los cursos de Conformación de la Región y Enfoques y Problemas en Arquitectura. Facultad de Arquitectura, Universidad oRT Uruguay. 


\section{RESUMEN \\ ABSTRACT}

Ya sea en cine, en televisión o en diversas obras de literatura y labor periodística sobre nuestra disciplina, la vivienda de interés social ha ocupado un lugar cargado de connotaciones en el amplio espectro de la memoria colectiva, connotaciones que parecen merecer cuando menos una revisión de su genealogía. ¿Es acaso uno de los mayores logros de la academia detractora del Movimiento Moderno que el programa insignia, depurado y defendido por las vanguardias de preguerra, cargue hoy con el estigma del fracaso y la obsolescencia? ¿En qué devino aquel potencial que Ludovico Quaroni, los BBPR y la generación tutelada por Ernesto Nathan Rogers reconocieron en los conjuntos habitacionales? ¿Ha desaparecido completamente el rol primordial que una vez tuvieron en la reconstrucción y renacimiento de las ciudades y la redefinición re-humanizante de las relaciones entre sus habitantes?’

Palabras clave: vivienda social, cine, neorrealismo, distopía, memoria colectiva.

Either in cinema, televisión or various literature and journalistic works about our discipline, the social housing has occupied a place loaded with connotations in the wide spectrum of the collective memory, connotations that seem to deserve at least a review on its genealogy. Is it by chance one major accomplishment of Modernism's detractor academy that the insignia programme, refined and defended by the pre-war avant-garde, carries nowadays with the stigma of failure and obsolescence? What has become of that potential that Ludovico Quaroni, the BBPRS and the generation guided by Ernesto Nathan Rogers recognized in the housing complexes? Has the essential role they once had in the reconstruction and rebirth of cities and in the re-humanizing redefinition of the relationships between its inhabitants completely dissapeared?

Keywords: Social Housing, Film Art, Neorrealism, Dystopia, Collective Memory.

1. El artículo se realizó en base a la Memoria Fin de Carrera, Facultad de Arquitectura, Universidad ORT Uruguay 2010, «La Decodificación Anacrónica: los complejos de vivienda y la experiencia en Uruguay». 
$Y$ hete aqui que se convierte en una ciudad de tamaño natural, encerrada dentro de la ciudad de antes: una nueva ciudad que se abre paso en medio de la ciudad de antes y la empuja hacia afuera.

Ítalo Calvino

$D$ ekalog, Fahrenheit 451 y El lenguaje de la arquitectura posmoderna. En estas tres obras -tanto como marco físico o caso incidental aislado y aun así ejemplar-, tres complejos habitacionales parecen representar la materialización de distopías o, más sencillamente, la explícita confirmación de un final. Desaparición de un paradigma, de un statu quo perimido, síntoma agonizante de una realidad sociocultural avasallada por la técnica que se ha olvidado, o que se intenta olvidar. ${ }^{1}$

\section{LA VIVIENDA COLECTIVA COMO ESPACIO ESCENOGRÁFICO}

En Dekalog, su director y creador, Krzystof Kieslowski, desarrolla una serie de diez cortometrajes, cada uno de ellos inspirado en uno de los Diez Mandamientos. La pretendida autonomía de cada entrega -transgredida únicamente por sutiles coincidencias temporoespaciales entre protagonistas de uno y otro capítulo- se encuentra hilada por una constante: un conjunto habitacional en un suburbio de Varsovia. La escala, el anonimato de los espacios comunes y la monocromía grisácea hacen del marco físico un cómplice del tono

1. Incluso la idea de muerte será empleada con total deliberación en uno de estos casos. melancólico con que el director describe la monótona y anodina vida de la última Polonia soviética.

Las lapidarias y dramáticas críticas por parte de exponentes posmodernos en las décadas del 70 y el 80, y experiencias con resultados en vivienda colectiva a gran escala, parecen haber contribuido a la fijación de determinadas imágenes y escenas en nuestra memoria colectiva, en la esfera social y la profesional. Las campañas a favor de la demolición del muy polemizado conjunto Corviale, en Roma, o la dimensión casi ficcional del tristemente célebre apodo «Ciudad Oscura», del Conjunto Piedrabuena en Buenos Aires, ${ }^{2}$ representan episodios que de algún modo prevalecen sobre otras diversas experiencias que rompen con el unánime balance negativo que la crítica al Movimiento Moderno ha establecido respecto de este tipo de programas de vivienda.

Por momentos parecen haber caído en el olvido algunas experiencias que, por su riqueza y complejidad formal o su sugestivo diálogo con lo vernáculo, han servido de escenario para ficciones cinematográficas con status «de culto», permitiendo al menos sugerir su valor como referente cultural.

Las riquísimas experiencias de Ludovico Quaroni, Mario Ridolfi y Carlo Aymonino en los barrios Tiburtino y Tuscolano, en la Roma de los años cincuenta y en la periferia milanesa, se convirtieron en escenarios recurrentes del cine neorrealista italiano de los cincuenta y

2. Proyectos de Mario Florentino en 1970 y del estudio M/SG/S/S/S/V en 1974 respectivamente. 
sesenta. Las primeras secuencias de emblemáticos largometrajes como // Sorpasso, de Dino Risi, y la Ragazza con la valigia, de Valerio Zurlini, son rodadas mayormente en sectores de los novísimos barrios periféricos de las ciudades italianas, que integraban el entorno rural a los suburbios bajo una lógica de predominio de proyectos de vivienda popular.

Nuevos barrios que surgen a partir de proyectos de vivienda popular a gran escala que buscan recomponer el escenario rural-suburbano desaparecido tras décadas de gobiernos fascistas interesados en acentuar la oposición campo-ciudad en intencional desmedro del primero. El particular paisaje de la periferia milanesa, resultante de urbanizaciones ex novo apenas pobladas aún y con casi nulos signos de apropiación por parte de sus aún escasos habitantes, sirvió a directores como Antonioni para establecer un paralelismo psicocósmico entre escenografía y el ritmo cansino y melancólico típico de su filmografía más esencial. Incluso en la actualidad, directores abiertamente influenciados por Antonioni -como el caso de Marina Spada en su película Come l'ombra- han recuperado ese contacto entre el cine y el espacio urbano de la periferia de Milán. En su arquitectura y espacialidad vuelven a hallar el cómplice ideal para plasmar en múltiples niveles la atmósfera anodina y melancólica que marca el ritmo de su relato.

La fluida dialéctica vernáculo-neorrealismo no es la única que reconoció en el espacio arquitectónico de la vivienda popular un valor icónico capaz de ser retratable a través del cine. En Brazil, Terry Gilliam halla en algunos espacios protagónicos del entonces flamante proyec- to de Bofill, Les Espaces d'Abraxas, el escenario ideal para materializar un futuro distópico sometido por el poder burocrático, desde un lente intencionadamente expresionista. Independientemente de la coincidencia o no con la propuesta que Bofill planteó desde el punto de vista estético, es innegable la profusa experimentación a nivel espacial y formal desde la que se abordó el proyecto. La monumentalidad con la que Bofill resuelve los espacios comunes, tanto circulatorios como de dispersión y contemplación, fue determinante para la atmósfera dramática e incluso onírica propia de la película de Gilliam.

Sin embargo, los desafíos que asume Bofill en este caso y en otros, como Walden 7 -en 1975- y en Les Temples du Lac -en 1986-, parecen propios de una actitud lejana y ajena a la práctica proyectual de vivienda popular en las últimas décadas.

\section{LA PERSISTENCIA POLÉMICA DEL «CONDENSADOR SOCIAL»}

Las utopías de orden social y grupos humanos necesitan ideas que den forma física a la noción de comunidad, como único modo de ordenar, sistematizar y hacer posible la vida en las nuevas aglomeraciones urbanas marcadas por nuevas actividades y sus complejas combinaciones. Fue precisamente desde la visión utópica de un hecho arquitectónico capaz de integrar las ideas de habitar, comunidad y vida cotidiana, que surgieron los primeros programas habitacionales definidos a partir de configuraciones de vivienda colectiva desde una dimensión social y popular. La integración de estas 


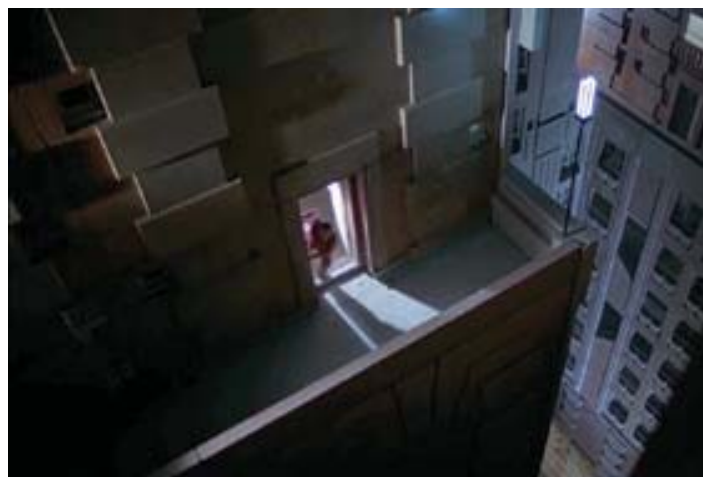

01

ideas se plantea aún en la actualidad como una serie de interrogantes que mantienen abierto el debate $y$ las instancias de desarrollo de nuevos proyectos como ámbitos de exploración a partir de los cuales reformular algunos planteos que cimentaron la génesis de la vivienda de interés social.

En Fahrenheit 451 François Truffaut elige a Alton West -la adaptación que el neobrutalismo inglés hizo de la Unité d'Habitation en el sureste de Londres- como escenario de la secuencia inicial de su película. Al igual que en Dekalog, la plástica y espacialidades hallables en este programa arquitectónico se hacen instrumentales para la reproducción psicocósmica de determinada atmósfera. En este caso, la adaptación de la distopía de Ray Bradbury se hace visible en la opresiva y enajenante realidad del régimen totalitarista en ejercicio del poder, que con la vivienda halla su eco en la supresión de todo rasgo de apropiación y particularización por parte de sus habitantes.

Con expresa intencionalidad o no, Truffaut muestra a la arquitectura como un instrumento más de control y orden de la sociedad, con la particularidad de que en este caso es la vivienda -estructurador por excelencia de la cotidianidad individual y grupal- y no un edificio gubernamental el símbolo de la opresión y la enajenación. Han tenido lugar numerosos proyectos de vivienda popular que durante el siglo xx han suscitado intensos debates en torno a este tema, y probablemente sea el Robin Hood Gardens uno de los más emblemáticos.

El conjunto de dos bloques proyectado por los Smithson en 1957, al igual que Alton West, responde al intento por parte de la municipalidad de Londres de revertir el caótico proceso de superpoblación y hacinamiento en los suburbios londinenses hacia la mitad del siglo xx. Una vez iniciado el plan urbanístico impulsado por la New Town Act, ${ }^{3}$ el crecimiento de la clase media londinense con cierto poderío económico tuvo el lugar y la infraestructura para consumarse más allá del Green Belt, ${ }^{4}$ quedando relegados de la intervención varios suburbios dentro del área metropolitana londinense, y la clase media baja que los poblaba.

Así como lo idearan años antes en el concurso al que presentaron el Golden Lane, en Robin Hood Gardens se planteó la misma idea de niveles de asociación como vehículo de crítica -con una explícita postura revisionista y

3. Plan promovido por el London City Council e iniciado en 1946. Estableció la creación de ciudades de dispersión limitada y gran autonomía para unificar funcional y estéticamente el desarrollo urbano más allá del área metropolitana de Londres.

4. Extensión de área verde que circunda algunas ciudades inglesas, pensada para regular la dispersión urbana y preservar la calidad ambiental de los suburbios. 
01.

\section{Película Brazil}

Terry Gilliam, 1985

IMAGEN: (๑) EMBASSY INTERNATIONAL PICTURES

02.

Película Fahrenheit 451.

IMAGEN: @ ANGLO ENTERPRISES VINEYARD FILM LTD.
François Truffaut, 1966.

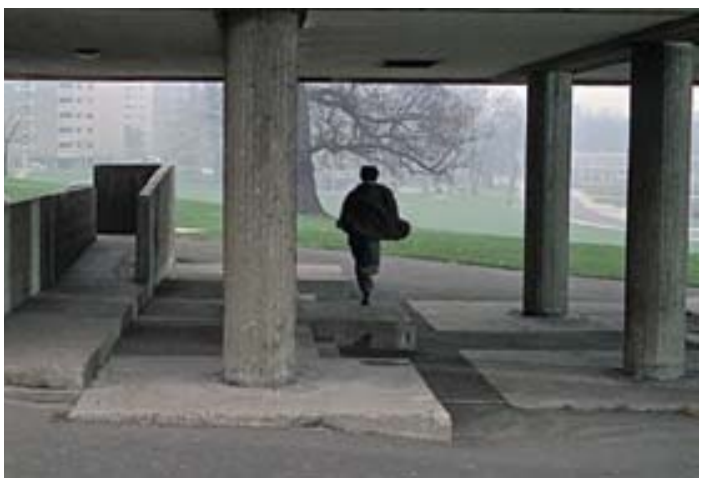

02

continuista- al reduccionismo de la Carta de Atenas. Ya desde su génesis, los Smithson conciben el proyecto habitacional como una ansiada instancia para reformular las lógicas de interrelación de grupos de personas, que a grandes rasgos había sido el espíritu del Manifiesto de Doorn. ${ }^{5}$ El reconocimiento del poder de la arquitectura sobre las relaciones entre sus habitantes y el uso del mismo como instrumento de cohesión y orden social ya habían sido planteados treinta años antes a partir de la idea de «condensador social», de Moiseii Guinzburg.

Salvando las diferencias sustanciales entre la realidad sociopolítica de la joven Unión Soviética de los años veinte y el consolidado sistema liberal inglés de posguerra, la idea primitiva que da lugar al proyecto de los Smithsons no es muy distinta a la planteada por Guinzburg décadas antes. En ambos casos coexiste la intención de posibilitar un control panóptico de determinados sectores de la sociedad y de intervenir con determinadas configuraciones espaciales en sus dinámicas sociales. Resulta evidente a su vez, y no incidentalmente, la rotunda distancia entre la resolución formal y de estilos en la vivienda popular suburbana inglesa y la de las viviendas en las coetáneas New Towns. El auge

5. Hereu, Pierre; Montaner, Josep Maria; Oliveras, Jordi. Textos de Arquitectura de la Modernidad. 3ra ed. San Sebastián: Nerea. P. 291 del neobrutalismo como canon estético de la nueva arquitectura moderna queda expresamente excluido de la imagen característica de aquella idea de ciudad, en favor del revival de las arquitecturas Tudor y neogóticas de fines del siglo XIX.

Las coincidencias conceptuales entre el Robin Hood Gardens y el extenso repertorio soviético en el cual se buscó reproducir la utopía de «condensador social» se convirtieron en un argumento útil para los detractores del Movimiento Moderno, que hicieron del proyecto la insignia del fracaso de paradigmas de arquitectura y ciudad que debían ser negados e incluso olvidados. La visión de Guinzburg, tan bien recibida en los primeros $\mathrm{CIAM}^{6}{ }^{6}$ fue en última instancia el catalizador de todo aquello que llevó a la crisis -inexorable muerte para los más acérrimos académicos- de la arquitectura moderna: la idea de un receptáculo de sectores marginales de la sociedad, más que un potenciador de sus relaciones e identidad.

La ironía del caso es que la sostenida polémica en torno al emblemático proyecto de los Smithson probablemente encuentre su fin no en el debate, sino en la

6. El Sindicato de Arquitectos Contemporáneos de la Unión Soviética tuvo desde los primeros CIAM una delegación invitada a instancias de Le Corbusier. 
03.

PÁGINA OPUESTA

\section{Conjunto habitacional VICMAN.}

Montevideo, Uruguay.

FOTOGRAFÍA: EMILIANO RUIZ VIROGA.

irrefrenable dinámica inmobiliaria de la metrópolis contemporánea, que reclama su terreno para continuar con el apremio gentrificador del pujante Canary Wharf.

\section{LAS EXPERIENCIAS DIVERGENTES EN EL ESCENARIO NACIONAL}

Los episodios relativamente recientes relacionados con la convulsionada relación del conjunto Euskalerría y su sector en Malvín Norte, o la demolición inexorable del Conjunto Habitacional INve 20, han fagocitado el espacio de debate que el empoderamiento económico y político de la Agencia Nacional de Vivienda, en consonancia con el Plan de Ordenamiento Territorial, han abierto en la actualidad al espacio disciplinar arquitectónico.

A priori pueden plantearse algunas hipótesis que podrían explicar el escaso interés que los programas de vivienda de interés social han suscitado en las últimas décadas en el ámbito de innovación proyectual. La conformación de una nueva identidad arquitectónica a nivel nacional, y las posibilidades de consolidación de posicionamientos estéticos o técnicos por parte de uno u otro arquitecto, han encontrado su ámbito de desarroIlo en otros programas. Existen algunas condicionantes que podrían explicar la segregación del programa en tanto ámbito de desarrollo creativo y de experimentación.

La amplia mayoría de las variadas políticas de vivienda que sucedieron al Plan Nacional de Vivienda de 1968 tuvieron como principal y lógica condicionante optimizar la eficiencia en el uso de los recursos económicos, dado el crónico y avanzado estado del déficit habitacional que sufría al país. Este factor, que no es ajeno a las coyunturas de otros países de la región y Latinoamérica, ha debido ser conciliado con las particularidades propias de la dialéctica entre técnica y tectónica. El espíritu con que Eladio Dieste aborda su ensayo Las tecnologías apropiadas y la creatividad da cuenta de la tímida cultura de apropiación de tecnologías en el ámbito local y las numerosas dificultades que presenta la dependencia de la importación de nuevas a un mercado reducido como el nuestro. En la vivienda de interés social han convergido la necesidad de reducir el costo de los materiales y procedimientos utilizados, con la estancada dependencia de tecnologías asimiladas y hoy consideradas tradicionales, pero nunca hechas totalmente propias. Como resultado, la acotada riqueza espacial y la reducida exploración tectónica han separado a las distintas formas de vivienda de interés social del potencial de experimentación y de hito urbano que una vez tuvieron.

Por otra parte, corresponde preguntarnos si la débil estructura urbana de los anillos periféricos de la capital se debe a la pérdida de una reflexión real sobre la dimensión territorial de los proyectos de vivienda de interés social. A diferencia de las bases sobre las que se desarrollaron las Garden Cities inglesas,? las bases teóricas medulares de los emprendimientos de vivienda popular han sido adaptadas fragmentada y selectivamente. De ese modo, los distintos proyectos de mediana a gran escala han devenido piezas de un puzle que completa

7. Más específicamente la depuración que Raymond Unwin y Barry Parker realizan de la propuesta original y hasta entonces irrealizada de Ebenezer Howard. 


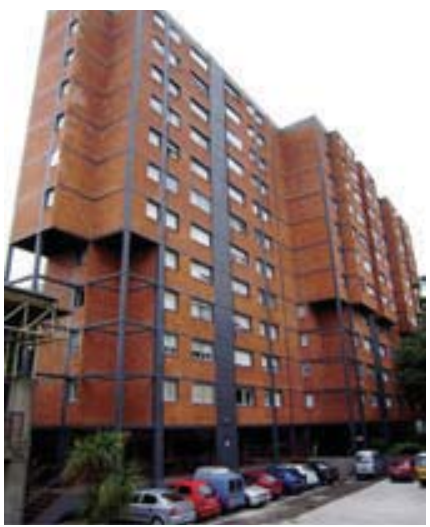

04.

los vacíos restantes con sucesivas unidades habitacionales. Éstas constituyen el elemento primario que viabiliza la dispersión territorial de la capital y convalida a su vez el rol de las áreas suburbanas resultantes.

Así, se reconoce en la periferia el potencial como soporte de nuevos emprendimientos de gran escala, y por su débil estructura urbana se hace de ella un terreno viable para la experimentación. Muchas veces esta licencia o libertad a la hora de experimentar en un terreno «virgen», décadas más tarde se transforma en un problema urbano de carácter endémico y difícilmente reversible. Sin embargo, algunos ejemplos confirman el rol reactivador que puede tener un complejo habitacional en zonas deprimidas o inactivas de la ciudad, densificándola e introduciendo nuevas dinámicas a las ya existentes.

Montevideo se expresa, entonces, como una ciudad en continuo comienzo, replicante precoz de las utopías europeas de progreso y en constante búsqueda de un modelo acertado. Consecuentemente se materializa una ciudad collage, como mezcla heterogénea de paisajes artificiales y grandes superficies suspendidas, aisladas o atrapadas en medio del proceso de gestión y urbanización.

La debilidad de la estructura urbana de algunas áreas de la ciudad hace que queden convertidas en escapa-
04.

\section{Conjunto Bulevar.}

Montevideo, Uruguay.

FOTOCRAFIA: EMILIANO RUIZ VIROGA. rates que exhiben la «muerte de las utopías» sobre comunidad y ciudad en manos de la realidad social, política y económica. La ilusión de las Villages of Unity, los Falansterios, las Garden Cities o la Ciudad Radiante ha culminado y vuelto a empezar con cada intento de realización material. La tendencia a evitar la reconversión tipológica e infraestructural en edificios de vivienda de interés social convierte algunas áreas de nuestra periferia en vacíos urbanos estancos en cuanto a la potencial discusión sobre su valor patrimonial.

Son dignas de mencionar, no obstante, algunas experiencias interesantes, no sólo desde el punto de vista espacial y estético, sino también en tanto propuesta funcional y de integración urbana.

Implantado en Malvín, sector que desde los años setenta ha devenido en un verdadero laboratorio de experimentación para la vivienda colectiva, se encuentra el conjunto de viviendas Vicman. ${ }^{8}$ Más allá de su cuidada resolución formal, del manejo de escalas y densidades menores que las de otros conjuntos en el sector, lo interesante en este caso es su contraposición a la hipótesis que asigna a la consolidación urbana del área intervenida la variable que determina el éxito o el fracaso de

8. Proyecto del arquitecto Alfredo Nebel, con la asesoría técnica del ingeniero Eladio Dieste. 
la experiencia. Tanto con la escala propuesta, como con el trazado de las calles internas y los límites físicos impuestos entre el conjunto y el espacio público, el proyectista y los habitantes del conjunto han logrado una explícita ruptura con el entorno circundante.

A priori, algunos datos no muy difícilmente verificables permitirían plantear la experiencia del conjunto VICMAN como exitosa: la atípica toma de partido con la que Nebel abordó el proyecto, en un sector de la ciudad en el que se habian propuesto hasta entonces densidades y escalas sustancialmente mayores; el excelente estado de conservación del conjunto, y la plena apropiación y uso de los espacios comunes por parte de sus habitantes.

La negación del entorno urbano en múltiples aspectos, permite buscar en otras variables las razones del éxito de la experiencia. La integración de los futuros usuarios a las primeras etapas del proceso proyectual es una de las condicionantes diferenciales de la obra de Nebel, con algunos antecedentes exitosos en el ámbito internacional. En la década del 70, las experiencias de Ralph Erskine con Byker Wall -Inglaterra-, y de Giancarlo de Carlo con Villaggio Matteotti -Italia-, conformaron una tendencia que, aunque breve, devino en resultados de gran interés tanto práctico como académico, de la llamada «arquitectura de la participación». Tanto Erskine como De Carlo abordan los respectivos proyectos desde la ruptura con el paradigma de usuario único y estandarizado propuesto por el funcionalismo y racionalismo de las vanguardias de entreguerras.

El éxito de estas experiencias inició en ese entonces un nuevo debate particularmente sensible en el ámbito de la vivienda colectiva y sobre el que aún no hay conclusión aparente. ¿Qué alcance real tiene el rol del usuario en tanto colaborador durante el proceso proyectual? El status profesional del arquitecto retoma, con la arquitectura de la participación, el complejo errar entre la figura del demiurgo hermético -catalogado por los más violentos reaccionarios de la posmodernidad como un útil instrumento en la diagramación «tiránica» de la sociedad- y el de un mero habilitador en un proceso bajo el control creativo y técnico del usuario final. El cómo devenir creativos libres y técnicos innovadores sin renunciar a la demostrada conexión con el usuario final permanece aún hoy como una interrogante sobre la cual resta mucho por definir.

En el caso del Conjunto Bulevar, ${ }^{9}$ por ejemplo, se logró una arriesgada combinación de parámetros formales y funcionales estableciéndose jerarquías claras en el

9. Proyecto de los arquitectos Ramiro Bascans, Arturo Villamil, Tomás Sprechmann y Héctor Viglieca. Construido entre 1970 y 1974. 
esquema circulatorio. Lo que en principio cumple un objetivo fundamentalmente funcional, da como resultado un gran nivel de complejidad en la resolución del conjunto a nivel de la planta baja, trascendiendo la literalidad de las barreras físicas explícitas -portones y enrejados- para separar funcionalmente circulaciones internas de la vía pública. Este complejo sistema y el éxito alcanzado a nivel funcional, y en tanto hito de la arquitectura de vivienda popular nacional, relativiza la pérdida de vigencia atribuida a las ideas planteadas en el Criteria for Mass Housing que los Smithson redactaron en 1957 para el Team 10.

Desde otro enfoque de menor complejidad conceptual, el caso del conjunto Parque Posadas se ha constituido en una de las experiencias más emblemáticas de vivienda de interés social en el ámbito nacional. Sin ánimo de desarrollar un análisis de este caso -para lo cual ya existe variada bibliografía al respecto-, resulta interesante detenerse en la depurada concordancia lograda entre el diseño y la técnica constructiva. La innovadora resolución ejecutiva del proyecto, capaz de integrar sistemas constructivos rotundamente distintos para su construcción, ${ }^{10}$ fue determinante en el abordaje de una escala sin precedentes en el ámbito nacional y en la compleja articulación de actores que ello implicó.

Así como en el Vicman, los conceptos esenciales de la toma de partido en el Parque Posadas son resultado de un proceso intelectual inherente al quehacer profesional. Más allá de la innovadora experiencia con promi-

10. Risso, Marta; Boronat, Yolanda. La vivienda de interés social en el Uruguay: 1970-1983. Montevideo: Fundación de Cultura Universitaria. P. 154 tentes usuarios en el proyecto del VIcman, la excelencia de su resolución constructiva y la bien lograda articulación entre bloques y parque llevan la marca del experimentado profesionalismo de Nebel y la sofisticada simplicidad del pensamiento de Dieste.

Si bien los antecedentes de la arquitectura de la participación en el ámbito nacional son más bien escasos y eran probablemente inexistentes en el momento de la realización del Vıcman, sí existen variados ejemplos que confirman que el reconocimiento de las múltiples complejidades desde las cuales ha de pensarse la arquitectura, y que han sido determinantes en el abordaje de proyectos de vivienda colectiva, continúan siendo potestad de la disciplina.

La prevalencia de la vivienda social como ámbito fecundo de discusión sobre las dimensiones y alcances del quehacer disciplinar debería abrir al menos una instancia de puesta en valor del programa arquitectónico, reconociéndose el rol que ha jugado no solamente en la configuración material de las ciudades y los grupos humanos que en ellas se articulan, sino también en el estatuto contemporáneo de la profesión y en el recorrido hacia el mismo.

\section{CONCLUSIÓN}

Ya sea en su representación cinematográfica o en el retrato que del tema se ha hecho en los medios de divulgación -especializados o no-, la vivienda de interés social ha sido frecuentemente el foco de debate sobre la crisis del relato moderno en nuestra disciplina. Basta con detenernos -tempranamente en nuestra formación 
teórica- en la conocidísima licencia que Jencks se toma en la apertura de El lenguaje de la arquitectura posmoderna. El conjunto habitacional ha sido convertido en sujeto del retrato más explícito, dramático e incluso animoso de la muerte de la arquitectura moderna.

En la destrucción del anónimo complejo en Dekalog, del Robin Hood Gardens o del Pruitt-Igoe citado por Jencks radica la liberación del sujeto de los perversos metarrelatos de la modernidad. ${ }^{11}$

Esto último no es más que otro metadiscurso afín a las más dramáticas posturas antimodernas. Concederle al debate teórico el convertir a la vivienda de interés social en estandarte de la herencia más sagrada o del error más imperdonable de la arquitectura moderna ha impedido reconocer en el ámbito de la práctica proyectual el potencial del programa. Permanece en discusión aún cómo recuperar su valor en tanto oportunidad de experimentación formal, y sobre todo como protagonista en la reproducción de determinada idea de ciudad, despegada del radical carácter de utopía, de los propuestos metadiscursos de la modernidad y de argumentos detractores que en su formulación han incurrido frecuentemente en lógicas igualmente perversas.

RECIBIDO: 10 de octubre de 2013 ACEPTADO: 15 de noviembre de 2013

11. Lyotard, Jean-Francois. La condición posmoderna: Informe sobre el saber. Barcelona: Planeta-De Agostini. p. 4 


\section{BIBLIOGRAFÍA}

CALVINO, Italo (1998). Las ciudades invisibles. Madrid: Ediciones Siruela.

COLQUHOUN, Alan (2005). La arquitectura moderna: Una historia desapasionada. Barcelona: Ed. GG.

FERNÁNDEZ, Roberto (1998). El laboratorio americano. Madrid: Biblioteca Nueva Editorial.

HEREU, Pierre, MONTANER, Josep Maria, OLIVERAS, Jordi. Textos de arquitectura de la modernidad (tercera edición) [c1994]. San Sebastián: Nerea.
JENCKS, Charles (1981). El lenguaje de la arquitectura posmoderna. Barcelona: Gustavo Gili.

LYOTARD, Jean-Francois (1998). La condición posmoderna: Informe sobre el saber. Barcelona: Planeta-De Agostini.

RISSO, Marta y BORONAT, Yolanda (1992). La vivienda de interés social en el Uruguay: 1970-1983. Montevideo: Fundación de Cultura Universitaria. 